\title{
Role of Plasma Presepsin, Procalcitonin and C-reactive Protein Levels in Determining the Severity and Mortality of Community-Acquired Pneumonia in the Emergency Department
}

\author{
Izzettin Hur ${ }^{1}$, Seda Ozkan ${ }^{2, *}$, Ali Halici ${ }^{3}$, Kerim Abatay ${ }^{4}$, \\ Eren Usul ${ }^{5}$, Esra Cetin ${ }^{6}$, Fevzi Nuri Aydin ${ }^{6}$
}

\author{
${ }^{1}$ Department of Emergency Medicine, \\ Ministry of Health Pursaklar State \\ Hospital, Ankara, Turkey \\ ${ }^{2}$ Department of Emergency Medicine, \\ Cerrahpasa Faculty of Medicine, Istanbul \\ University-Cerrahpasa, Istanbul, Turkey \\ ${ }^{3}$ Department of Emergency Medicine, \\ Ministry of Health Polatlı State Hospital, \\ Ankara, Turkey \\ ${ }^{4}$ Department of Emergency Medicine, \\ Ministry of Health Muş State Hospital, \\ Muș, Turkey \\ ${ }^{5}$ Department of Emergency Medicine, \\ Ministry of Health Dr. Nafiz Korez Sincan \\ State Hospital, Ankara, Turkey \\ ${ }^{6}$ Department of Clinical Biochemistry, \\ Diskapi Yildirim Beyazit Training \& \\ Research Hospital, Ankara, Turkey

\section{*Correspondence sedacil@gmail.com (Seda Ozkan)}

\begin{abstract}
Objective: In this study, we aimed to explore the role of the plasma presepsin level in patients with community-acquired pneumonia during admission to the emergency department in assessing the diagnosis, severity, and prognosis of the disease. In addition, we wanted to investigate the relationship of presepsinin with procalcitonin, C-reactive protein and pneumonia severity scores. Methods: One hundred twenty-three patients over the age of 18 who presented with a diagnosis of pneumonia to the emergency department were included in the study. The vital signs, symptoms, examination findings, background information, laboratory results, and radiological imaging results of the patients were recorded. The 30day mortality rates of the patients were determined. Results: A statistically significant difference was found between the presepsin levels of the patients diagnosed with pneumonia and those of healthy subjects $(\mathrm{p}<0.05)$. The plasma presepsin levels of the patients who died $(8.63 \pm 6.46)$ were significantly higher than those of the patients who lived $(5.82 \pm 5.97)(\mathrm{p}<0.05)$. The plasma procalcitonin and $\mathrm{C}$-reactive protein levels of the dead patients were significantly higher than those living $(\mathrm{p}<0.05)$. A presepsin cut-off value of $3.3 \mathrm{ng} / \mathrm{mL}$ for 30-day mortality was established (AUROC, 0.65 ; specificity, 45\%; sensitivity, $82 \%$ ). Procalcitonin is the most successful biomarker in the determination of mortality (AUROC, 0.70). A significant correlation was available between presepsin and lactate, $\mathrm{C}$-reactive protein and procalcitonin $(\mathrm{p}<0.05)$. There was a significant correlation between the Pneumonia Severity Index values and presepsin levels $(p<0.001, r=0.311)$. Conclusion: The plasma presepsin level can be utilized for diagnosing community-acquired pneumonia. Plasma presepsin, procalcitonin and C-reactive protein levels can be used to predict the severity and mortality of community-acquired pneumonia.
\end{abstract}

\section{Keywords}

Biomarkers, Pneumonia, Emergency department, Prognosis, Mortality

\section{Introduction}

Despite the recently developed treatments, communityacquired pneumonia exhibits a serious course with high morbidity and mortality rates [1]. It is one of the major reasons for sepsis and death in developed countries.
Making an accurate, objective, and early diagnosis in patients with community-acquired pneumonia is crucial to assessing the severity and scope of the disease and predicting the level and outcome of the treatment [2].

Pneumonia severity scores have been developed to aid in determining the severity and prognosis of the disease. The 
TA B L E 1. Comparison of demographic and laboratory data of the patients.

\begin{tabular}{|c|c|c|c|c|}
\hline & $\begin{array}{l}\text { All Patients } \\
(n=123)\end{array}$ & $\begin{array}{c}\text { Dead Patients } \\
\text { mean } \pm \text { SD } \\
(\text { min-max })\end{array}$ & $\begin{array}{c}\text { Living Patients } \\
\text { mean } \pm \text { SD } \\
(\text { min-max })\end{array}$ & $\mathbf{p}$ \\
\hline Age & $\begin{array}{l}71.54 \pm 13.36 \\
(28-92)\end{array}$ & $78.1 \pm 9.5(58-92)$ & $69 \pm 13.7(28-91)$ & $<0.001$ \\
\hline Systolic B.P (mmHg) & $\begin{array}{l}120 \pm 27 \quad(70- \\
184)\end{array}$ & $114 \pm 19(70-160)$ & $123 \pm 22(70-184)$ & 0.063 \\
\hline Diastolic B.P (mmHg) & $70 \pm 20(40-130)$ & $64 \pm 10(40-90)$ & $72 \pm 13(50-130)$ & 0.001 \\
\hline Pulsation & $\begin{array}{l}100 \pm 29(60- \\
160)\end{array}$ & $101 \pm 23(60-160)$ & $99 \pm 20(69-150)$ & 0.70 \\
\hline Fever $\left({ }^{\circ} \mathrm{C}\right)$ & $\begin{array}{l}37.1 \pm 0.9(26- \\
41)\end{array}$ & $37.2 \pm 0.95(36-39.5)$ & $37.1 \pm 0.88(35.6-41)$ & 0.646 \\
\hline Respiratory Rate & $22 \pm 6(12-33)$ & $22 \pm 4.7(15-33)$ & $21 \pm 3.3(12-30)$ & 0.46 \\
\hline Oxygen Saturation & $86 \pm 13(54-99)$ & $82.7 \pm 9.2(58-99)$ & $85.9 \pm 10.6(54-99)$ & 0.41 \\
\hline \multicolumn{5}{|l|}{ Comorbidity } \\
\hline Hypertension n (\%) & $61(49.6)$ & $14(23)$ & $47(77)$ & 0.249 \\
\hline Diabetes Mellitus n (\%) & $30(24.4)$ & $9(30)$ & $21(70)$ & 0.74 \\
\hline CAD n $(\%)$ & $38(30.9)$ & $8(21.1)$ & $30(78.9)$ & 0.275 \\
\hline Congestive Heart Failure n (\%) & $26(21.1)$ & $7(26.9)$ & $19(73.1)$ & 0.926 \\
\hline Cerebrovascular Accident n (\%) & $15(12.2)$ & $4(26.7)$ & $11(73.3)$ & 0.928 \\
\hline Chronic Kidney Disease n (\%) & $9(7.3)$ & $3(33.3)$ & $6(66.7)$ & 0.692 \\
\hline Malignancy n (\%) & $9(7.3)$ & $6(66.7)$ & $3(33.3)$ & 0.007 \\
\hline COPD n $(\%)$ & $54(43.9)$ & $11(20.4)$ & $43(79.6)$ & 0.111 \\
\hline \multicolumn{5}{|l|}{ Laboratory values } \\
\hline WBC & $\begin{array}{l}13400 \pm 6782 \\
(2600-41200)\end{array}$ & $\begin{array}{l}13558 \pm 6806(2600- \\
31300)\end{array}$ & $\begin{array}{l}13.339 \pm 6810 \\
(2700-41200)\end{array}$ & 0.793 \\
\hline $\mathrm{Hb}$ & $\begin{array}{l}12.83 \pm 2.31 \\
(6.1-18.2)\end{array}$ & $\begin{array}{l}12.5 \pm 2.11 \\
18.2)\end{array}$ & $\begin{array}{l}12.9 \pm 2.38 \text { (6.2- } \\
17.9)\end{array}$ & $0.342 *$ \\
\hline Het & $\begin{array}{l}39.6 \pm 7.3(18.5- \\
59.8)\end{array}$ & $38.9 \pm 6.95(19-57)$ & $\begin{array}{l}39.9 \pm 7.45 \text { (18.5- } \\
59.8)\end{array}$ & $0.462 *$ \\
\hline PLT & $\begin{array}{l}256056 \pm 13683 \\
(26000-676000)\end{array}$ & $\begin{array}{l}219205 \pm 125078 \\
(26000-628000)\end{array}$ & $\begin{array}{l}270134 \pm 139163 \\
(70000-676000)\end{array}$ & 0.067 \\
\hline Ure & $\begin{array}{l}65.25 \pm 37.8(19- \\
206)\end{array}$ & $89.1 \pm 42(22-206)$ & $56.1 \pm 31.8(19-186)$ & $<\mathbf{0 . 0 1}$ \\
\hline Creatine & $\begin{array}{l}1.30 \pm 0.61 \\
(0.52-5.23)\end{array}$ & $\begin{array}{l}1.49 \pm 0.8 \text { (0.74- } \\
5.23)\end{array}$ & $\begin{array}{l}1.22 \pm 0.5 \quad(0.52- \\
3.24)\end{array}$ & 0.024 \\
\hline $\mathrm{Na}$ & $\begin{array}{l}136.37 \pm 6.68 \\
(108-172)\end{array}$ & $\begin{array}{l}139.4 \pm 8.7(128- \\
172)\end{array}$ & $\begin{array}{l}135.2 \pm 5.3(108- \\
145)\end{array}$ & 0.014 \\
\hline K & $\begin{array}{l}4.33 \pm 0.71(2.5- \\
6.34)\end{array}$ & $\begin{array}{l}4.38 \pm 0.84 \text { (2.5- } \\
6.34)\end{array}$ & $\begin{array}{l}4.31 \pm 0.66 \text { (2.92- } \\
6.03)\end{array}$ & $0.648 *$ \\
\hline Glucose & $\begin{array}{l}164.43 \pm 86.06 \\
(71-495)\end{array}$ & $\begin{array}{l}163.5 \pm 60.6 \text { (71- } \\
310)\end{array}$ & $\begin{array}{l}164.7 \pm 94.2 \text { (74- } \\
495)\end{array}$ & 0.198 \\
\hline AST & $\begin{array}{l}69.65 \pm 328.13 \\
(8-3643)\end{array}$ & $\begin{array}{l}158.3 \pm 620.4 \\
3643)\end{array}$ & $35.7 \pm 26.6(8-153)$ & 0.249 \\
\hline ALT & $\begin{array}{l}54.58 \pm 233.39 \\
(5-2546)\end{array}$ & $\begin{array}{l}111.9 \pm 437.6 \\
2546)\end{array}$ & $32.6 \pm 44(5-336)$ & 0.782 \\
\hline
\end{tabular}

* The Student t-test was performed for Hb, Htc, and K. The Mann Whitney U test was regarded as significant for other data $p<0.05$. 
TA B L E 2. Comparisons of the biomarkers and severity scores of dead and living patients.

\begin{tabular}{lcccc} 
Biomarkers & All Patients & $\begin{array}{c}\text { Dead Patients } \\
\text { mean } \pm \text { SD (min-max) }\end{array}$ & $\begin{array}{c}\text { Living Patients } \\
\text { mean } \pm \text { SD (min-max) }\end{array}$ & p \\
\hline Presepsin $(\mathrm{ng} / \mathrm{mL})$ & $6.77 \pm 6.27(0-27.8)$ & $8.63 \pm 6.46(0.17-24.4)$ & $5.82 \pm 5.97(0-27.8)$ & $\mathbf{0 . 0 1 3}$ \\
Procalcitonin $(\mathrm{ng} / \mathrm{mL})$ & $10.1 \pm 22.1(0-100)$ & $18.1 \pm 30.4(0-100)$ & $6.5 \pm 17.5(0-100)$ & $<\mathbf{0 . 0 0 1}$ \\
CRP $(\mathrm{mg} / \mathrm{L})$ & $157.4 \pm 158.3(5.75-1280)$ & $210.9 \pm 132.3(7.87-483)$ & $138 \pm 166(5.75-1280)$ & $\mathbf{0 . 0 0 1}$ \\
ESR $(\mathrm{mm} / \mathrm{h})$ & $41.7 \pm 26(2-120)$ & $43.6 \pm 23.5(2-111)$ & $41.6 \pm 27.3(2-120)$ & 0.53 \\
\hline Lactate $(\mathrm{mmol} / \mathrm{L})$ & $2.49 \pm 1.82(0.7-11.2)$ & $3.15 \pm 2.61(0.7-11.2)$ & $2.24 \pm 1.39(0.8-7.9)$ & 0.069 \\
PSI & $140.19 \pm 35.98(61-240)$ & $159.6 \pm 33.4$ & $132.7 \pm 34.3$ & $<\mathbf{0 . 0 0 1}$ \\
CURB65 (median; IQR) & $2 ; 1(0-5)$ & $02: 01.3$ & $2: 01$ & 0.27
\end{tabular}

Mann Whitney U test, Student t-test, $p<0.05$ is significant.

TA B L E 3. The ROC analysis of biomarkers and pneumonia severity scores for mortality.

\begin{tabular}{|lcccccc} 
Biomarkers & AUC & SE & \%95 CI & Cut off & Sensitivity & Specificity \\
\hline Presepsin & 0.646 & 0.0558 & 0.555 to 0.730 & $>3.3$ & 82.3 & 44.9 \\
\hline Procalcitonin & 0.703 & 0.052 & 0.614 to 0.782 & $>0.9$ & 76.4 & 62.9 \\
\hline CRP & 0.689 & 0.0541 & 0.599 to 0.770 & $>179$ & 58.8 & 77.5 \\
\hline Lactate & 0.606 & 0.0602 & 0.514 to 0.693 & $>2.3$ & 55.8 & 67.4 \\
\hline PSI & 0.722 & 0.048 & 0.627 to 0.816 & $>96.5$ & 97.1 & 86.5 \\
\hline CURB-65 & 0.561 & 0.056 & 0.451 to 0.671 & $>1.5$ & 76.5 & 64 \\
\hline
\end{tabular}

TA B L E 4. The correlation of biomarkers and pneumonia severity scores.

\begin{tabular}{|c|c|c|}
\hline \multicolumn{3}{|c|}{ Presepsin } \\
\hline & $\mathbf{r}$ & $\mathbf{p}$ \\
\hline Procalcitonin & $0.612 *$ & $<0.01$ \\
\hline CRP & $0.339 *$ & $<0.01$ \\
\hline ESR & 0.09 & 0.32 \\
\hline Lactate & $0.182^{*}$ & 0.04 \\
\hline CURB65 & 0.041 & 0.65 \\
\hline PSI & $0.311^{*}$ & $<0.01$ \\
\hline \multicolumn{3}{|c|}{ PSI } \\
\hline & $\mathbf{r}$ & $\mathbf{p}$ \\
\hline Presepsin & $0.311^{*}$ & $<0.01$ \\
\hline Procalcitonin & $0.385^{*}$ & $<0.01$ \\
\hline CRP & 0.092 & 0.31 \\
\hline ESR & 0.039 & 0.67 \\
\hline Lactate & 0.163 & 0.07 \\
\hline CURB65 & 0.03 & 0.74 \\
\hline
\end{tabular}

Spearman Correlation Test, $p<0.05$ is significant.

Pneumonia Severity Index (PSI) is a risk scoring system that determines the 30-day mortality and morbidity of pneumonia by dividing patients into 5 different risk classes and is based on the results of the PORT study that was prospectively conducted on 14199 patients in 1997. The criteria in this scoring system include the demographic features, physical examination findings, comorbidities, laboratory results, and radiological results of the patients [3, 4]. The high number variables necessary for PSI scoring restricts its use in the emergency department. Compared with the PSI, the CURB 65 scoring system is easier to apply in the emergency department, but its prognostic value is low. CURB65 uses confusion, blood urea nitrogen (BUN), respiratory rate, blood pressure, and age as criteria. Although the prediction performance of the PSI scoring system has been shown to be better, the CURB 65 scoring system has been proposed for use in the emergency department because of its ease of use and because its results are close to those of PSI scoring [5, 6]. The difficulty of using PSI scoring in the emergency department and the low prognostic value of CURB 65 increases the importance of using of biomarkers to assess pneumonia.

C-reactive protein (CRP) and procalcitonin (PCT) are the most robust and widely used biomarkers in communityacquired pneumonia. Especially PCT provides much more sensitive and specific information for infection than previous systemic biomarkers. However, due to some limitations of procalcitonin, new biomarker search studies for pneumonia are ongoing [1].

CD-14 is a protein of approximately $55 \mathrm{kDa}$ that is present in the membranes of mononuclear cells, and it serves as a high-affinity receptor to lipopolysaccharides (LPS) and the lipopolysaccharide/lipopolysaccharide binding protein complex (LPBP). The LPS-LPBP-CD14 complex separates from the cell membrane and is released into the circulation to form soluble CD14 (sCD14). Another SCD14 produced by plasma protease activity is called sCD14-subtype (presepsin). Presepsin consists of a $13 \mathrm{kDa}$ polypeptide fragment from the terminal end of CD14. Pre- 
TA B L E 5. Comparison of the biomarkers according to the PSI and CURB65 stages.

Comparison of the Biomarkers According to the PSI Stages

\begin{tabular}{|c|c|c|c|c|c|}
\hline & Stage II $(n=3)$ & Stage III $(n=8)$ & Stage IV $(n=39)$ & Stage V $(n=73)$ & p \\
\hline & mean \pm SD & mean \pm SD & mean \pm SD & mean \pm SD & \\
\hline & $(\min -\max )$ & $(\min -\max )$ & $(\min -\mathbf{m a x})$ & $(\min -\max )$ & \\
\hline Presepsin & $1.1 \pm 1.5(0.2-2.8)$ & $3 \pm 2.7(0-6.5)$ & $5.3 \pm 5.9(0-27.8)$ & $7.9 \pm 6.4(0.2-27.8)$ & 0.002 \\
\hline Procalcitonin & $0.3 \pm 0.4(0-0.7)$ & $4.7 \pm 9.6(0-27)$ & $4.6 \pm 14.6(0-86)$ & $13.4 \pm 26.3(0-100)$ & 0.001 \\
\hline CRP & $36.1 \pm 34.4(14.1-75.7)$ & $150.4 \pm 131.6(35.3-449)$ & $156.9 \pm 226.8(5.7-1274)$ & $165.1 \pm 120.7(6.9-483)$ & 0.07 \\
\hline ESR & $26.6 \pm 13.6(11-36)$ & $41.1 \pm 28.3(11-88)$ & $41.6 \pm 28(2-120)$ & $43.3 \pm 25.8(2-114)$ & 0.7 \\
\hline Lactate & $2.7 \pm 1.6(1.1-4.3)$ & $2 \pm 1.1(1.1-4.4)$ & $2 \pm 1(0.9-5)$ & $2.8 \pm 2.2(0.7-11.2)$ & 0.5 \\
\hline \multicolumn{6}{|c|}{ Comparison of the Biomarkers According to the CURB65 Stages } \\
\hline & & Stage I $(n=41)$ & Stage II $(n=52)$ & Stage III $(n=26)$ & $\mathbf{p}$ \\
\hline & & mean \pm SD & mean \pm SD & mean \pm SD & \\
\hline & & (min-max) & (min-max) & (min-max) & \\
\hline Presepsin & & $6.8 \pm 7(0-27.8)$ & $6.2 \pm 5.5(0-22.6)$ & $7.2 \pm 6.4(0.2-18.2)$ & 0.77 \\
\hline Procalcitonin & & $4.8 \pm 24.8(0-100)$ & $10.5 \pm 21.6(0-100)$ & $8.1 \pm 20.4(0-100)$ & 0.58 \\
\hline CRP & & $122.7 \pm 102.1(7.3-430)$ & $190 \pm 206(5.7-1280)$ & $150.8 \pm 119.8(14.8-435)$ & 0.29 \\
\hline ESR & & $39 \pm 22(2-82)$ & $44.5 \pm 31.5(2-120)$ & $42.6 \pm 20.8(2-84)$ & 0.87 \\
\hline Lactate & & $2.2 \pm 1.3(0.8-7.9)$ & $2.7 \pm 1.9(0.7-9.5)$ & $2.7 \pm 2.4(0.9-11.2)$ & 0.35 \\
\hline
\end{tabular}

The Kruskall Wallis Test, $p<0.05$ is statistically significant.

sepsin does not have lipopolysaccharide binding properties, so it cannot be captured by anti-CD14 antibodies; thus, this free molecule can be used as a biomarker. Numerous studies have shown that presepsin levels are increased in the early stages of bacteremia and sepsis, and presepsin has been proposed as a biomarker for routine use [7-11].

In this study, we aimed to explore the role of the plasma presepsin level of patients with community-acquired pneumonia during admission to the emergency department in assessing the diagnosis, severity, and prognosis of the disease.

\section{Materials and methods}

Complying with the principles of the "World Medical Association Declaration of Helsinki," this study was carried out in accordance with the research guidelines and was approved by the Ethics Committee of Ankara Diskapi Training and Research Hospital on March 19, 2018 (numbered 47/09). Patients diagnosed with pneumonia between March 20, 2018, and May 20, 2018, were included in the study. After establishing a diagnosis of pneumonia according to clinical and laboratory findings, 123 patients in total were included in the study, and all of the patients were older than 18 years. Forty-four healthy people were included in the control group. In addition to newly emerging pulmonary infiltration indicated by chest radiography and at least two symptoms or a pyrexia complaint, the patients suspected of infection based on laboratory signs whose infection seemed to have a pulmonary focus received a diagnosis of pneumonia.

Patients who were hospitalized in the last two weeks, pregnant women, patients who received immunosuppression treatment, patients who received antibiotic therapy, patients with pulmonary phthisis, and patients with diagnoses that might be confused with pneumonia such as pulmonary thromboembolism and decompensated heart failure were excluded from the study. Moreover, among the patients whose comorbidities included COPD, because it could affect the presepsin level, and those observed to experience COPD attack were also not included in the study. Among the patients who were previously diagnosed with COPD and taking a drug to treat it, those who exhibited wheezing, rhonchi, or prolonged expirium in the physical examination, whose blood gas $\mathrm{pCO}_{2}$ value was more than 60 , and who showed clinical relief with inhaler treatment were also excluded from the study.

The patients included in the study were kept informed and provided informed consent during the first admission or when the patient's acute complaints abated.

The background of the patients was obtained directly from the patients or the relatives who are responsible for their care. The patients underwent physical examinations and laboratory investigations. The vital signs, symptoms, examination findings, personal background, laboratory results, and radiological surveys of the patients were recorded. No intervention was performed during the patients' follow-up and treatment process. The patients' PSI and CURB 65 scores were calculated.

The presepsin level of each patient was measured within 2 hours after admission by drawing approximately $5 \mathrm{ml}$ of blood. The blood samples were centrifuged at $3000 \mathrm{rpm}$ for 15 minutes, transferred to Eppendorf tubes with a serum 


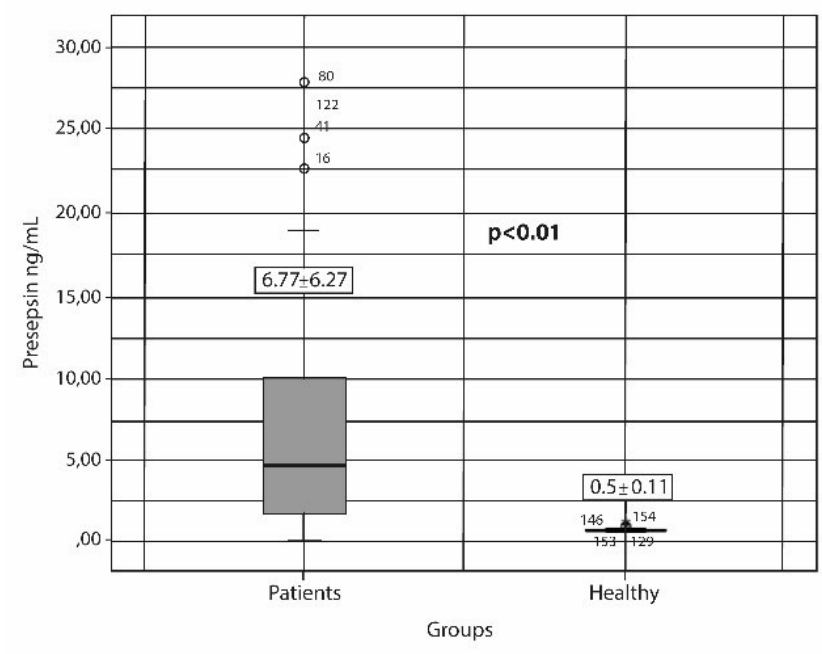

A

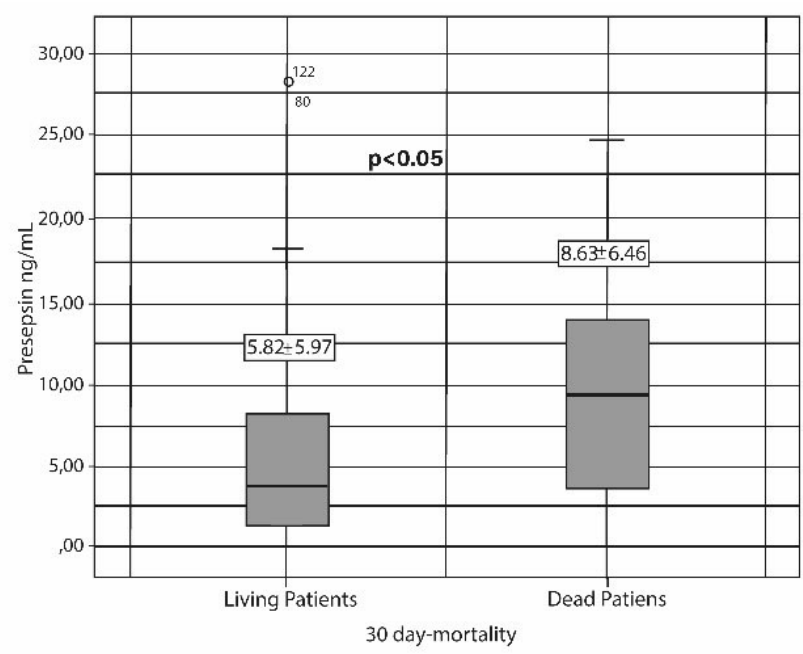

B

FIGURE 1. A- Statistically significant difference was ascertained between the plasma presepsin levels of the pneumonia patients and of the healthy control group. B- Plasma presepsin levels of patients who died were found to be significantly higher compared to those living.

pipette, and frozen and stored at $-80{ }^{\circ} \mathrm{C}$. Serum presepsin levels were measured in our institution's microbiology laboratory using the Human Presepsin ELISA MBS766136 coded kit, which can measure 0.156-10 ng/ml and has a sensitivity of $<0.094 \mathrm{ng} / \mathrm{ml}$.

To determine mortality, the patients were observed for 30 days, and any mortality within 30 days was recorded.

\subsection{Statistical methods}

For the statistical analysis of the obtained data, SPSS 24.0 (Statistics Program for Social Scientists) was used. To test normality, the Kolmogorov Smirnov test was used for groups with more than 30 patients, and the Shapiro-Wilk test was used for groups with less than 30 patients. The Mann Whitney U test was performed to compare the data not normally distributed, and Student's t-test was used to compare the normally distributed data, with $\mathrm{p}<0.05$ regarded as statistically significant. The Chi-Square test was used to compare the frequency data between the two groups, with $\mathrm{p}<0.05$ regarded as statistically significant. Using presepsin, the correlation between infection biomarkers and pneumonia severity scores was assessed. Because the data were not normally distributed, the Spearman test was performed as the correlation test.

\section{Results}

A total of 123 subjects were included in the study. The mean age of the subjects was $71.54 \pm 13.36$ years $(28-92) ; 57 \%$ of the patients were male $(n=70)$. The demographic features, vital signs, and laboratory values of the patients are shown in Table 1.

The symptoms of the patients were recorded at the time of admission to the hospital, and $67.5 \%(n=83)$ of the patients had a cough, and $57.7 \%(\mathrm{n}=71)$ of them had sputum com- plaints. For respiratory sounds, the auscultation findings were positive in $93.5 \%(\mathrm{n}=115)$ of the patients, and the most frequent auscultation finding was rales, in $62.6 \%(\mathrm{n}=$ 77) of the patients. Pneumonic infiltration was observed on chest radiography in $89.4 \%(n=110)$ of the patients.

A statistically significant difference was found between the plasma presepsin levels of the patients with pneumonia (mean: $6.77 \pm 6.27(0-27.8)$ ) and those of the healthy control group (mean: $0.5 \pm 0.11(0.41-1.01))(\mathrm{p}<0.001$, Figure 1A).

It was observed that $27.6 \%(n=34)$ of the subjects included in the study died within 30 days. When examining the relation between patient age and mortality, a significant difference was found between the mean age of the patients who died and the mean age of the patients who lived ( $\mathrm{p}<$ 0.001 ). The presence of chronic diseases in the patients as determined from their personal backgrounds was compared with mortality, and a significant relationship was found between malignancy and mortality $(\mathrm{p}=0.007$, Table 1$)$.

When examining the 30-day mortality, it was observed that the PSI scores of patients who died and those of patients who lived were significantly different $(p<0.001$, Table 2$)$. However, no significant difference was detected between the CURB65 scores of patients who died and those of patients who lived ( $\mathrm{p}>0.05$, Table 2).

The erythrocyte sedimentation rate (ESR) and C-reactive protein (CRP), lactate, procalcitonin, and presepsin values were compared between the patients who died and those who lived. The plasma presepsin levels of patients who died were significantly higher than those of patients who lived (Fig. 1B). The procalcitonin and CRP levels of the patients who died were also significantly higher than those of the patients who lived ( $p<0.05$, Table 2$)$.

ROC analysis was performed to determine the relationship between presepsin, procalcitonin, CRP, ESR, and lac- 
TA B LE 6. A multivariate model for predicting 30-day mortality.

\begin{tabular}{lcccccccc} 
& B & SE & Wald & df & P value & Odds ratio & $\begin{array}{r}\text { 95\% confidence interval } \\
\text { Lower Limit }\end{array}$ & $\begin{array}{l}\text { Upper Limit } \\
\text { Presepsin }\end{array}$ \\
\hline & 0.027 & 0.038 & 0.498 & 1 & 0.48 & 1.027 & 0.953 & 1.108 \\
Procalcitonin & 0.008 & 0.01 & 0.601 & 1 & 0.438 & 1.008 & 0.988 & 1.028 \\
CRP & 0.003 & 0.001 & 3.306 & 1 & 0.069 & 1.003 & 1 & 1.005 \\
PSI & 0.02 & 0.007 & 7.949 & 1 & 0.005 & 1.02 & 1.006 & 1.034 \\
\hline
\end{tabular}

tate values and 30-day mortality. The AUROC value was the highest for procalcitonin (AUROC: 0.70). A presepsin cut-off value of 3.3 was established for 30-day mortality, with values of 0.65 for AUC, $45 \%$ for specificity, and $82 \%$ for sensitivity. The AUC value of PSI in determining the 30-day mortality was 0.72 . (Table 3 ).

A significant correlation was found between presepsin and lactate, CRP, and procalcitonin $(\mathrm{p}<0.05$, Table 4$)$. In addition, a poor but significant correlation was detected between PSI values and plasma presepsin levels $(\mathrm{p}<0.001)$. No relationship was found between presepsin and CURB65 scores (Table 4).

Biomarkers were compared according to PSI and CURB65 stages. In accordance with the PSI stages, a significant difference was found between plasma presepsin and procalcitonin levels $(\mathrm{p}<0.05$, Table 5$)$.

In the multivariate analysis performed to determine the 30-day mortality, PSI was found to be the most effective independent parameter (Table 6).

\section{Discussion}

Because the presepsin level responds quickly to systemic inflammation, it has been described as an early diagnostic biomarker of sepsis [12,13]. Many studies have stated that presepsin can be utilized for the diagnosis of infection and sepsis [11, 14, 15]. However, there are a limited number of studies focusing on pneumonia and presepsin. Klauche et al. reported that plasma presepsin levels were significantly higher in patients with a diagnosis of pneumonia in intensive care than in patients with non-infectious respiratory failure [16]. In this study we conducted in the emergency department, we compared the plasma presepsin levels of patients with pneumonia with those of healthy individuals, and we found that the plasma presepsin level was significantly higher in patients with pneumonia.

In this study, the 30-day mortality rate of communityacquired pneumonia was recorded as $28 \%$. While the 30 day mortality rate was $22 \%$ in the study performed by Bo Liu et al. [10], Metersky et al. [17] reported a mortality rate of $12.1 \%$. Moreover, Zhou et al. reported a mortality rate of $22 \%$ [18]. In the study conducted by Zhou et al., the PSI value of patients with serious pneumonia was $132.0 \pm 33.7$, while the PSI value of patients with nonserious pneumonia was 94 [18]. The mean PSI value of the patients in our study was $140.19 \pm 35.98$ (61-240). The high PSI values of our subjects likely explains the high mortality rate. Most of the patients included in our study were followed up in the yellow and red zones in the emergency department. Because patients in the green zone stay in the hospital for a short time, it was more difficult to reach and include them in the study. In addition, patients with good clinical findings refused to participate in the study because of concerns about giving blood, undergoing additional examinations, wasting time in the hospital, and sharing personal information. These factors are likely why the mortality rate in our study was higher than those in the literature.

The PSI is an effective scoring system to predict mortality in community-acquired pneumonia. In our study, while a statistically significant difference was found between the PSI scores of the patients who died and those who lived, this significant difference was not found for CURB 65 scores. Likewise, Ugajin et al. [12] reported a significant difference between the PSI scores of patients who died and those of patients who lived. Moreover, Bo Liu et al. [10] stated that CURB 65 alone fell short in predicting mortality. Even though the prediction performance of the PSI scoring system has been shown to be better, the use of the CURB 65 scoring system has been proposed because of its ease of use and because its results are close to those of PSI scoring [5].

In their study, Behnes et al. found a significant relationship between presepsin, procalcitonin, and CRP and mortality [19]. In another study, the presepsin levels of patients with pneumonia who died were reported to be significantly higher than those of patients who were living [12]. However, in this study, no significant difference was detected between the CRP levels of the patients who died and those of the patients who lived [12]. In our study, the presepsin, procalcitonin, and CRP levels of the patients who died were significantly higher than those of the patients who lived. These findings indicate that there was no difference between the three biomarkers in terms of mortality in pneumonia cases.

In our study, in the determination of mortality, the AUC value of presepsin was $0.646(3.3 \mathrm{ng} / \mathrm{mL})$. It was not found to be superiority to procalcitonin (AUC: 0.703 ). Likewise, in the study performed by Klouche et al., presepsin was not found to be superior to procalcitonin (cut-off: $714 \mathrm{pg} / \mathrm{mL}$ ) [16]. Furthermore, Bo Liu et al. [10] did not find presepsin (AUC: 0.672 , cut-off: $498.5 \mathrm{pg} / \mathrm{mL}$ ) to be superior to procalcitonin (AUC: 0.683 ) in the determination of 28day mortality. In their study, Ugajin et al. [12] reported 
a presepsin AUC value of 0.742 (cut-off: $470 \mathrm{pg} / \mathrm{mL}$ ). However, they included only hospitalized patients in their study [12]. They also reported an AUC value for CRP of 0.606. The AUC value for CRP in our study was 0.689 . For the 30-day mortality prediction, no significant superiority of presepsin, procalcitonin, and CRP over another was observed in our study. Klouche et al. [16] studied patients with pneumonia in the intensive care unit, which is why the cut-off value was high in their study. The profiles of the patients included in a study have an effect on cut-off values. As a result, studies show that procalcitonin is the most successful biomarker in the determination of mortality.

Behnes et al. [19] found a significant correlation of presepsin with both procalcitonin and CRP. In their study, Ugajin et al. [12] reported that a significant relationship exists between presepsin and CRP. The correlations between presepsin and both procalcitonin and CRP were confirmed to be statistically significant in our study as well. CRP and procalcitonin are two major biomarkers used in the diagnosis of community-acquired pneumonia. Procalcitonin is a peptide precursor of calcitonin that is released from parenchymal cells as a response to bacterial toxins in bacterial infections. Procalcitonin is utilized to guide the prognosis and antibiotic treatment of communityacquired pneumonia $[1,6]$. In this study, we compared the plasma presepsin level with both the procalcitonin and CRP levels to determine its role in prognosis. The results confirmed that presepsin is as effective a biomarker as procalcitonin in community-acquired pneumonia.

In addition, we determined PSI as the most effective independent parameter in determining mortality in the multivariate test. In our study, there was a significant correlation between the plasma presepsin level and the PSI. Additionally, a significant difference was detected between presepsin levels according to PSI stages. In the study performed by Bo Liu et al. [10], the presepsin level was found to be significantly higher in patients with severe pneumonia than in non-severe patients. In their study, Ugajin et al. [12] reported a significant correlation between the presepsin level and the PSI. In our study, in addition to presepsin, although a relation was found between procalcitonin and the PSI, no such relation was found between the other biomarkers and the PSI. In the study performed by Bo Liu et al. [10], the procalcitonin and lactate values were found to be high in severe pneumonia cases. No significant differences between presepsin levels were detected according to CURB 65 score stages. In a previous report, there was no significant difference between stage 1 and stage 2 of the CURB 65, but a significant difference was detected between stage 3 and other stages of CURB 65 [12]. Because the PSI comprises numerous parameters, it is more reliable than CURB 65 in predicting the prognosis of communityacquired pneumonia [6]. The correlation of presepsin with the PSI indicates that the plasma presepsin level can be used to predict the prognosis of the disease.

\section{Conclusion}

In summary, based on the data obtained, the plasma presepsin level can be used to diagnose community-acquired pneumonia. In addition, plasma presepsin, procalcitonin and CRP levels can be used to predict the severity and mortality of community-acquired pneumonia. The plasma procalcitonin level is the most successful biomarker in the determination of mortality. We propose that presepsin is as effective as procalcitonin and the PSI for determining the severity and mortality of pneumonia.

\section{LIMITATIONS}

The most important limitations of this study were the low number of patients and the short duration of our study. Additional diseases of the patients may have affected the results.

\section{ACKNOWLEDGEMENTS}

Thank numerous individuals participated in this study.

\section{CONFLICTING INTEREST}

The authors declare that there are no conflicts of interest.

\section{AUTHOR CONTRIBUTIONS}

The authors contributed equally to this study.

\section{ETHICAL APPROVAL}

Complying with the principles of the "World Medical Association Declaration of Helsinki", this study was carried out in accordance with the research rules by taking the approval of the Ethics Committee dated 19.03.2018 and numbered 47/09 at the Ankara Diskapi Yildirim Beyazit Training and Research Hospital.

\section{FUNDING INFORMATION}

For this study, we received financial support from the scientific research projects (No. 69/1 dated April 24, 2018) support program of our hospital.

\section{INFORMED CONSENT}

All participants were informed about the study. Verbal consent was from the patients. There was no intervention in the follow-up and treatment of the patients.

\section{REFERENCES}

[1] Karakioulaki M, Stolz D. Biomarkers in Pneumonia-Beyond Procalcitonin. Int J Mol Sci. 2019;20:2004. 
[2] Mandell LA, Wunderink RG, Anzueto A, et al. Infectious diseases society of America/American Thoracic Society consensus guidelines on the management of community acquired pneumonia in adults. Clin Infect Dis. 2007;44:27-72.

[3] Fine MJ, Auble TE, Yealy DM, et al. A prediction rule to identify lowrisk patients with community-acquired pneumonia. N Engl J Med. 1997;336:243-250.

[4] Jones BE, Jones J, Bewick T, et al. CURB-65 Pneumonia Severity Assessment Adapted for Electronic Decision Support. Chest. 2011;140:156-163.

[5] Aujesky D, Auble TE, Yealy DM, et al. Prospective comparison of three validated prediction rules for prognosis in community-acquired pneumonia. Am J Med. 2005;118:384-392.

[6] Keramat F, Ghasemi Basir HR, Abdoli E, et al. Association of serum procalcitonin and C-reactive protein levels with CURB-65 criteria among patients with community-acquired pneumonia. Int J Gen Med. 2018;11:217-223.

[7] Halıcı A, Hür İ, Abatay K, et al. The role of presepsin in the diagnosis of chronic obstructive pulmonary disease acute exacerbation with pneumonia. Biomark Med. 2020;14:31-41.

[8] Shirakawa K, Naitou K, Hirose J, et al. Presepsin (sCD14-ST): development and evaluation of one-step ELISA with a new standard that is similar to the form of presepsin in septic patients. Clin Chem Lab Med. 2011;49:937-939.

[9] Mussap M, Puxeddu E, Burrai P, et al. Soluble CD14 subtype (sCD14-ST) presepsin in critically ill preterm newborns: preliminary reference ranges. J Matern Fetal Neonatal Med. 2012;25:51-53.

[10] Liu B, Chen YX, Yin Q,et al. Diagnostic value and prognostic evaluation of Presepsin for sepsis in an Emergency department. Crit Care. 2013;17:R244.

[11] Romualdo LG, Torrella PE, Gonzales MV, et al. Diagnostic accuracy of presepsin (soluble CD14 subtype) for prediction of bacteremia in patients with systemic inflammatory response syndrome in the Emergency Department. Clin Biochem. 2014;47:505-508.
[12] Ugajin M, Matsuura Y, Matsuura K, et al. Impact of initial plasma presepsin level for clinical outcome in hospitalized patients with pneumonia. J Thorac Dis. 2019;11:1387-1396.

[13] Wu J, Hu L, Zhang G, et al. Accuracy of Presepsin in Sepsis Diagnosis: A Systematic Review and Meta-Analysis. PLoS One. 2015;10:e133057.

[14] Kweon OJ, Choi JH, Park SK, et al. Usefulness of presepsin (sCD14 subtype) measurements as a new marker for the diagnosis and prediction of disease severity of sepsis in the Korean population. J Crit Care. 2014;29:965-970.

[15] Nair GB, Niederman MS. Year in review 2013: critical care respiratory infections. Crit Care. 2014;18:572.

[16] Klouche K, Cristol JP, Devin J, et al. Diagnostic and prognostic value of soluble CD14 subtype (Presepsin) for sepsis and communityacquired pneumonia in ICU patients. Ann Intensive Care. 2016;6:59..

[17] Metersky ML, Waterer G, Nsa W, et al. Predictors of In-Hospital vs Post discharge Mortality in Pneumonia. Chest. 2012;142:476-481.

[18] Zhou H, Guo S, Lan T, et al. Risk stratification and prediction value of procalcitonin and clinical severity scores for community-acquired pneumonia in ED. Am J Emerg Med. 2018;36:2155-2160.

[19] Behnes M, Bertsch T, Lepiorz D, et al. Diagnostic and prognostic utility of soluble CD 14 subtype (presepsin) for severe sepsis and septic shock during the first week of intensive care treatment. Crit Care. 2014;18:507.

How to cite this article: Izzettin Hur, Seda Ozkan, Ali Halici, Kerim Abatay, Eren Usul, Esra Cetin, et al. Role of Plasma Presepsin, Procalcitonin and C-reactive Protein Levels in Determining the Severity and Mortality of Community-Acquired Pneumonia in the Emergency Department. Signa Vitae. 2020;16(2):61-68. doi:10.22514/sv.2020.16.0034. 